\title{
Relações de comercialização entre compradores e produtores de leite do sul de Minas Gerais
}

\author{
Commercialization relations between buyers and milk producers of the south of \\ Minas Gerais
}

\section{Relations commerciales entre les acheteurs et les producteurs de lait du Sud de Minas Gerais}

\section{Relaciones de comercialización entre compradores y productores de leche del sur de Minas Gerais}

\author{
Leandro Carvalho Bassotto ${ }^{1}$ \\ Marina Ariente Angelocci \\ Luciana de Paula Naves ${ }^{1}$ \\ Fernando Ferrari Putti ${ }^{3}$
}

Recebido em 30/07/2017; revisado e aprovado em 16/12/2017; aceito em 14/02/2018 DOI: http://dx.doi.org/10.20435/inter.v0i0.1671

\begin{abstract}
Resumo: O objetivo deste estudo foi analisar as relações existentes entre as empresas compradoras de leite e os produtores rurais de oito cidades do Sul de Minas Gerais e verificar a influência dessas relações em diversos fatores de produção nos resultados econômicos provenientes da produção leiteira e outras áreas da atividade necessárias para a produção láctea. Para isso, foram realizadas entrevistas de campo com 115 produtores rurais das cidades de Campestre, Caldas, Elói Mendes, Paraguaçu, Poço Fundo, Poços de Caldas, Ipuiuna e Machado. Após a coleta de dados, foram realizadas análises para verificar a relação existente entre diversos fatores de produção que sofrem impactos a partir das relações de comercialização entre os produtores de leite e as empresas compradoras do produto na região. Os resultados permitem concluir que diversos fatores necessários para o processo produtivo são influenciados pelo relacionamento entre os agentes citados, e o resultado dos processos de comercialização podem impactar não somente os lucros, mas também outras áreas da atividade leiteira necessárias para o processo produtivo.
\end{abstract}

Palavras-chave: administração rural; gestão comercial; desenvolvimento agropecuário; pecuária leiteira.

Abstract: The objective of this study was to analyze the existing correlations of milk buyers with rural producers in eight cities in the South of Minas Gerais and to verify the influence of these relationships on several factors of production in the economic results from dairy production and other areas of activity required for dairy production. For this, field interviews were conducted with 115 rural producers from the cities of Campestre, Caldas, Elói Mendes, Paraguaçu, Poço Fundo, Poços de Caldas, Ipuiuna and Machado. After the data collection, analyzes were carried out to verify the relationship between several factors of production that are impacted by the commercial relations between milk producers and the companies purchasing the product in the region. The results allow us to conclude that several factors necessary for the productive process are influenced by the relationship between the mentioned agents and the result of the commercialization processes can impact not only the economic results but also on other areas of the dairy activity required for the productive process. Keywords: rural administration; commercial management; agricultural development; livestock.

Résumé: Le but de cette étude était d'analyser la corrélation du lait d'acheter des entreprises avec les agriculteurs de 8 villes dans le sud du Minas Gerais et l'influence de ces relations dans divers facteurs de production dans les résultats économiques de la production de lait et d'autres domaines d'activité nécessaire pour la production laitière. Pour ce faire, des interviews sur le terrain ont été menées auprès de 115 agriculteurs des villes de Campestre, Caldas, Elói Mendes, Paraguaçu, Poço Fundo, Pocos de Caldas, Ipuiúna et Machado. Après la collecte des données, des analyses ont été réalisées pour étudier la relation entre les différents facteurs de production qui sont impactés de la commercialisation des relations entre les producteurs de lait et les sociétés d'achat du produit dans la région. Les résultats suggèrent que plusieurs

\footnotetext{
${ }^{1}$ Universidade José do Rosário Vellano (UNIFENAS), Alfenas, Minas Gerais, Brasil.

2 Faculdade Anhanguera Educacional, Santa Bárbara D’Oeste, São Paulo, Brasil.

${ }^{3}$ Faculdade de Ciências e Engenharia, Tupã, São Paulo, Brasil.
} 
facteurs nécessaires au processus de production sont influencés par la relation entre les agents ci-dessus et le résultat des processus de marketing peut avoir un impact non seulement économique, mais aussi d'autres secteurs de l'élevage laitier nécessaires au processus de production.

Mots-clés: administration rurale; gestion commerciale; développement agricole; élevage laitier.

Resumen: El objetivo de este estúdio fue analizar las correlaciones existentes de las empresas compradoras de leche com los productores rurales de ocho ciudadesdelsur de Minas Gerais y verificar La influencia de estas relaciones en diversos factores de producción em los resultados económicos provenientes de laproducción lechera y otras áreas de La actividad necesarias para la producción láctea. Para esto, se realizaron entrevistas de campo con 115 productores rurales de lãs ciudades de Campestre, Caldas, Elói Mendes, Paraguaçu, Poço Fundo, Poços de Caldas, Ipuiuna y Machado. Después de La recolección de datos, se realizaron análisis para verificar La relación existente entre diversos factores de producción que sufren impacto a partir de las relaciones de comercialización entre productores de leche y las empresas compradoras Del producto en La región. Los resultados permiten concluir que diversos factores necesarios para El proceso productivo son influenciados por La relación entre los agentes citados y el resultado de los procesos de comercialización pueden impactar no solo los resultados económicos, sino también otras áreas de La actividad lechera necesarias para el proceso productivo.

Palabras clave: administración rural; gestión comercial; desarrollo agropecuário; ganadería lechera.

\section{INTRODUÇÃO}

À medida que produtividades mais altas são atingidas, percebe-se que o campo e, em especial, a pecuária leiteira vêm atingindo grandes taxas de retorno sobre o capital investido e remunerações superiores ao que o produtor poderia ganhar, caso estivesse trabalhando nos grandes centros urbanos. É possível perceber que a atividade leiteira é, dentro do agronegócio nacional, uma importante fonte geradora de renda e emprego (DAL MAGRO et al., 2013).

Essa ideia é complementada por Oliveira, Gomes e Medeiros (2007) ao dizer que os produtores de leite apresentam seus negócios inviabilizados se não conseguirem trabalhar efetivamente os custos de produção e suas estruturas tecnológicas, mantendo alto nível de inovação no campo.

Bland et al. (2015) pesquisaram o setor leiteiro do Rio Grande do Sul para a caracterização das propriedades leiteiras, onde constataram que pouco se conhece a respeito da atividade na região, o que alertou para a necessidade de trabalhos que permitam conhecer com mais profundidade as características das propriedades leiterias, proporcionando assim novos estudos que auxiliem gargalos da produção e comercialização.

Com efeito, diante da importância da pecuária leiteira e das inúmeras adversidades que assolam o setor, tem-se a necessidade de estudos que aprofundem as questões estratégicas relacionadas à área, permitindo assim o desenvolvimento econômico e social dos produtores e municípios ligados à bovinocultura. Com isso, este estudo visa responder à seguinte pergunta: Que áreas da pecuária leiteira podem ser influenciadas pelas relações de comercialização da produção láctea nas propriedades do Sul de Minas Gerais? Serão investigadas as seguintes hipóteses: a busca de informações fortalece a produção de leite no Sul de Minas Gerais? As empresas compradoras de leite podem contribuir e incentivar o desenvolvimento das fazendas leiteiras?

O objetivo do presente trabalhou foi investigar a pecuária leiteira do Sul de Minas Gerais de modo a tornar possível a identificação de quais os fatores ligados à comercialização e à relação entre compradores e produtores de leite poderiam influenciar no desenvolvimento dessa atividade por meio da utilização de diversos recursos tecnológicos e de conhecimento. 


\section{REFERENCIAL TEÓRICO}

Assim como em outros segmentos, o agronegócio é um setor cujo foco deve convergir com os aspectos relacionados à gestão e à competitividade, estando seus responsáveis envolvidos e empenhados com todas as estratégias necessárias para o desenvolvimento empresarial. Macedo, Rodrigues e Silveira (2011) confirmam isso ao dizer que os tomadores de decisões devem estar atentos e bem informados sobre todas as questões que envolvam os negócios da empresa.

Atrelado a isso, tornam-se cada vez mais necessárias medidas gerenciais que permitam avaliar com maior profundidade a competitividade das empresas que disputam os mesmos mercados. Córdova et al. (2012) citaram que a globalização é o principal processo que encoraja as empresas a buscarem forças competitivas mais eficazes.

Em estudo desenvolvido por Pinto e Gonçalves (2015), a globalização é apresentada como uma das responsáveis pelas profundas transformações na economia mundial, em que as modificações mais significativas ocorreram nas duas últimas décadas do século passado. É válido ressaltar que essas mudanças ocorrem em todos os eixos do conhecimento, influenciando diversas etapas dos processos que vão desde a produção até a comercialização. Crusafón (2012) apresenta o termo globalização como tópico para muitos campos do conhecimento nos quais existem várias perspectivas e vários fenômenos.

Sobre esse prisma, Hermida e García (2016) apresentam a globalização como a direção e o ritmo de "progresso" que geram um grande sistema socialmente mediado. Essa mediação é notada quando se observam as grandes evoluções tecnológicas cujas aplicações sociais chegam a ser antagônicas. Serrano e Hermida (2015) complementam ao dizer que o social gera influência nas mudanças que transformam a sociedade.

Com isso, surgem os usos tecnológicos que permitem constatar a grande performance da comunicação por via dos recursos interativos. Arruda, Girão e Lucena (2015) afirmam que a comunicação das pessoas em todo o mundo tem sofrido grande modificação em decorrência, entre outros, do uso das mídias sociais, o que pode ser verificado por diversos outros autores que afirmam que a utilização da internet tem influenciado drasticamente na comunicação social das pessoas (RECUERO, 2009; HUTTER et al., 2013).

Assim tem-se o conceito de macroambiente ou ambiente externo, entendido por Machado (2011) como todos os aspectos externamente relacionados à organização e que influenciam direta ou indiretamente na condução das empresas. Leão e Mello (2010) complementam ao dizerem que esse ambiente [externo] exige conhecimento das oportunidades e ameaças para as organizações e necessitada de constantes monitoramentos.

Conforme Neves (2012), a análise do macroambiente deve estar focada no estudo das principais forças que impactam as empresas, bem como qual a medição da capacidade destas empresas em enfrentá-las. Em outras palavras, pode-se compreender que são necessários estudos sobre os impactos das ameaças e oportunidades como partes do ambiente externo da empresa, para que se possa conhecer a influência desses fatores no cotidiano das organizações.

O conhecimento profundo das questões apresentadas é necessário para que se possa estar mais atento às reais modificações do ambiente, que são cada vez mais dinâmicas. Segundo Tidd, Bessant e Pavitt (2008), o cenário vem se modificando ao passo que empresas com mais conhecimentos e avanços tecnológicos conseguem obter maior vantagem competitiva, pois são capazes de inovar com novos produtos e serviços e nos modos como criam essas ofertas.

Com efeito, análises macroambientais mais profundas permitem e auxiliam o processo de inovação, na qual a empresa se fortalecerá e poderá se manter atenta a tudo o que acontece no 
ambiente competitivo em que esteja inserida, pois, de acordo com Deziot (2014), a inovação é uma importante estratégia de cunho competitivo com especial relevância para a capacidade de ter seu foco no cliente.

A considerar que, desde os primórdios da humanidade, já existia a essência do conhecimento do mercado que ansiava pelo suprimento das necessidades embasadas na cultura e nos valores e, a partir disso, definir critérios de consumo e produção (LOPES; PACAGNAN, 2014), pode-se ponderar que, nos dias atuais, conhecer apenas o ambiente externo da organização não é o suficiente, visto que os aspectos internos também são importantes. Com isso, o microambiente empresarial torna-se de especial relevância para que seja devidamente estudado e compreendido, como mecanismo que propicia o crescimento e a máxima eficiência produtiva das organizações.

Segundo Morales (2015), o conhecimento do mercado interno pode ser a chave para o fracasso ou sucesso futuro das empresas, visto que é uma importante ferramenta de estudo, pois permite maior estabilidade estrutural para desenvolver a atividade empresária. Assim, o ambiente interno, ou microambiente refere-se a todos os pontos fortes e fracos que compõem a empresa, em toda a amplitude organizacional.

Ao se referir ao ambiente interno, Leão e Mello (2010) evidenciam o conceito de controles formais e informais, no qual o primeiro são todas as ferramentas e procedimentos que podem ser reconhecidos e aplicáveis à organização. Já o segundo são comportamentos individuais ou coletivos dos colaboradores que influenciam no microambiente, destacando-se o autocontrole (ajustamento dos comportamentos individuais em prol dos objetivos organizacionais), o controle social (interações e perspectivas inter-relacionais nos subgrupos das organizações) e o controle cultural (padrões normativos da empresa que regem os funcionários). Boehs e Segatto-Mendes (2007, p. 203) ressaltam que a "construção de sentido informal é geralmente necessária para prover às partes o acesso às incertezas envolvidas, à natureza e à confiabilidade de cada parte, aos direitos e aos deveres, bem como à eficiência e à equidade esperada de cada contraparte".

Ainda segundo Leão e Mello (2010), embora tanto o ambiente externo quanto o interno da empresa sejam importantes, é no primeiro que podem ser realizadas as mensurações (e avaliações) de metas estabelecidas e desempenho, de modo que ações corretivas possam ser implementadas, quando necessário.

Juntas, a análise das fortalezas (S), fraquezas (W), oportunidades (O) e ameaças (T), conhecidas com Análise SWOT (acrônimo das palavras acima citadas no idioma inglês). Trata-se de uma ferramenta gerencial de grande importância para diagnosticar diversas ações estratégicas dentro de uma empresa, apresentando pontos fortes, fracos e a melhorar dentro dos ambientes interno e externo (ZALUSKI et al., 2017). Azzopardi e Cortis (2013) chamam a atenção para a importância dessa ferramenta administrativa que oferece uma visão geral da situação da organização, bem como na visão sistêmica desta.

\section{MATERIAL E MÉTODOS}

Foi realizada uma pesquisa quantitativa com abordagem descritiva com produtores de leite do Sul de Minas Gerais. Foram entrevistados 115 produtores de leite nos meses de dezembro de 2016 a março de 2017, em oito cidades sul mineiras: Caldas, Campestre, Poços de Caldas, Ipuiuna, Machado, Paraguaçu, Elói Mendes, Poços de Caldas e Poço Fundo.

Foi elaborado um questionário que buscou obter o maior número possível de informações. As perguntas foram organizadas de modo que os produtores pudessem escolher entre algumas 
opções ou apresentar outras respostas diferentes daquelas presentes nos questionários, respeitando as particularidades de cada propriedade.

Os dados foram inicialmente tabulados em uma planilha eletrônica do Software Microsoft Excel. Foi atribuído um score para as respostas presentes em todas as questões quantitativas que variou de 1 a 7. Foi utilizado o software Minitab para realizar a análise estatística sendo considerada a Correlação de Pearson representada nesse trabalho pela letra " $r$ ". Essa análise gera um coeficiente que permite verificar se a correlação é positiva, negativa ou neutra. Foi adotado $\alpha=5 \%$ para verificar a significância entre as variáveis. Antes de realizar a análise estatística, foi verificada a normalidade dos dados, por meio do teste de Kolmogorov-Smirnov, caso os dados não apresentassem normalidade, seria realizada a transformação. No caso do presente artigo, não houve a necessidade.

Os valores oriundos da análise estatística obedecem à variação presente entre-1 e 1 em que, quanto mais próximo de 1 , maior é a correlação diretamente proporcional e, quanto mais próximo de-1, maior a correlação inversamente proporcional entre as variáveis. $\mathrm{O}$ algarismo 0 representa a neutralidade, cujos valores, quanto mais próximos de 0 são, menor é a correlação existente entre as variáveis em estudo.

As perguntas realizadas no texto encontram-se no Quadro 1.

Quadro 1 - Perguntas quantitativas realizadas aos produtores de leite que participaram da pesquisa. Alfenas, MG, 2017

\begin{tabular}{|l|}
\hline Realiza compras direto da fábrica? \\
\hline Quem compra seu leite? \\
\hline Por que vende leite para essa empresa compradora? \\
\hline Venderia seu leite para outras empresas compradoras? \\
\hline Faz investimento em qualidade do leite? \\
\hline Como é a alimentação dos animais? \\
\hline Fornece ração aos animais (vacas em lactação, vacas secas e animais em crescimento)? \\
\hline Como são realizados os controles administrativos (anotações) da atividade leiteira? \\
\hline Quais são os controles realizados? \\
\hline Possui outra fonte de renda? \\
\hline Quais recursos tecnológicos são utilizados na sua atividade leiteira? \\
\hline
\end{tabular}

Fonte: Elaborado pelos autores.

Nessas perguntas, foram abordadas questões sobre as formas de comercialização do leite e os motivos pelos quais os produtores são motivados a venderem para os compradores que com eles negociam. Foram considerados a fidelidade dos produtores de leite junto às empresas compradoras, a precificação, as opções de escolha e outras informações apresentadas que permitissem identificar as razões pelas quais os produtores vendem a produção para os compradores.

Ainda sobre o quesito comercialização, foram contempladas na pesquisa informações que dizem respeito a investimentos em qualidade do leite, na qual foi indagado aos produtores sobre a realização de compras de insumos, se é via atacados, e a realização de investimento em qualidade do leite.

Por fim, sobre as condições de conhecimento envolvidas nas propriedades em estudo, foi considerada a adoção de práticas de registro das principais informações que são geradas nas propriedades e que podem ser úteis para a tomada de decisões e para o melhor gerenciamento da atividade leiteira. 


\section{RESULTADOS}

Uma variável analisada $(r=0,191, p=0,041)$ correlaciona a fidelidade ao registro manual das informações realizadas. Foi possível inferir que, à medida que o relacionamento entre produtor e empresa compradora do leite aumenta e a lealdade daquele por essa se fortalece, aumentam na mesma proporção os registros manuais das informações na propriedade. Entende-se que, caso a fidelidade diminua, as propriedades rurais diminuirão o registro das informações.

A mesma conclusão pode ser observada ao se analisar os resultados obtidos pela correlação entre a fidelidade do produtor e o registro das informações pelos técnicos de assistência técnica e extensão rural $(r=0,203, p=0,030)$. Os resultados indicaram que ações existentes entre compradores e vendedores, ao fortalecerem a relação de fidelidade entre ambos, permitem que os recursos possam ser mais bem ofertados às propriedades

Quando considerada a correlação existente entre a fidelidade do produtor e as propriedades que não executam nenhum tipo de anotação cujo $r=-0,223$ ( $p=0,017)$, este mostrou que, quanto mais leal à empresa compradora do leite o produtor for, menor será a condução das atividades pecuárias relacionadas à produção de leite sem a utilização de mecanismos de registro e controle das informações geradas nas propriedades. Assim, foi possível perceber que a relação que se forma entre comprador e vendedor de leite fortalece ou enfraquece o sistema produtivo, influenciando não somente em aspectos ligados à comercialização, mas também sobre mecanismos e metodologias de gestão que podem ser mais ou menos aproveitadas a depender dessas relações.

Ao serem analisadas as correlações existentes entre a fidelidade e as formas que os produtores se utilizam para buscar mais informações sobre seus negócios, mercado do leite etc., constatou-se que a busca de informações por meio dos recursos televisivos obteve $r=0,223$ $(p=0,017)$. Isso significa dizer que o aumento de fidelização do produtor para com a empresa compradora de leite influencia-Ihe diretamente a necessidade em obter informações sobre sua atividade de atuação, de modo que consiga permanecer mais atento e focado ao sistema de produção da atividade agropecuária.

Essa conclusão também foi reafirmada com o $r=0,206$ ( $p=0,028)$, que envolve as variáveis fidelização e busca de informações por meio de revistas e jornais que aumentou proporcionalmente, indicando que os compradores possivelmente fornecem mecanismos que estimulam o acesso e a interação dos agricultores com sistemas de informação e comunicação, revistas técnicas, jornais, informativos, entre outros.

A fidelidade no fornecimento de leite dos produtores para as empresas compradoras também pôde ser correlacionada com a utilização de recursos de tecnologias dentro das propriedades, dentre os quais o primeiro foi a utilização de tanques de esfriamento e conservação do leite, conhecidos como tanques de expansão. O resultado da correlação entre eles indicou $r=0,231(p=0,013)$ e permitiu compreender que as relações de comercialização entre os produtores e as empresas compradores do leite influenciaram diretamente na utilização de equipamentos que agregam valor e melhoram a qualidade do leite produzido devido à redução das instabilidades do mercado. Além disso, a utilização de ordenhadeiras que transportam o leite do úbere da vaca no momento da extração até os tanques de expansão, também conhecida como ordenhadeiras canalizadas, apresentou correlação com a fidelização, indicados pelo $r=$ $0,225(p=0,016)$ que aumentou proporcionalmente em relação ao nível de lealdade dos clientes para com os compradores de leite. 
Foi possível identificar também a correlação entre a fidelidade dos produtores participantes da pesquisa com a utilização de práticas de adubação de pastagens com o objetivo de maximizar a produção vegetal nas propriedades. O $r=0,384(p<0,0001)$ indicando que, quanto mais fidelizados os produtores forem, mais preocupados estarão com a intensificação das áreas agricultáveis destinadas à produção vegetal necessárias para a pecuária leiteira.

Outro quesito analisado na pesquisa e que apresentou resultados de especial relevância são aqueles ligados à comercialização do leite. Ao serem observadas as variáveis sobre qual o motivo de os produtores venderem leite para os compradores indicados na pesquisa, as respostas apresentadas que dizem respeito à pontualidade no pagamento pela empresa compradora em questão, quando relacionada com a variável a falta de opções de empresas compradoras de leite na região, foi possível atestar que, com $r=-0,208(p=0,026)$, quanto mais as empresas compradoras forem pontuais, menor será a percepção dos produtores sobre as condições de inexistência de outros compradores que possam comprar o leite deles. Significa dizer que, quanto mais pontuais forem as empresas, maiores serão as opções de escolha dos produtores por empresas compradoras de leite, fato esse que permitiu a inferência de que existem entidades de comércio lácteo nas regiões analisadas que possuem o hábito de atrasar o pagamento aos produtores, motivo de grande descontentamento deles.

Outra avaliação realizada sobre esse aspecto foi a correlação existente entre a falta de pontualidade das empresas que compram o leite e a condição de aumento nos preços pagos por elas aos produtores rurais. O $r=-0,263(p=0,005)$ das variáveis indicou que, diante da condição de inversão proporcional, teve-se o resultado de que quanto mais pontuais as empresas indicaram ser, menos elas pagaram pelo litro de leite produzido. Quando considerou as condições de não atraso no pagamento pelo leite comprado e o investimento em qualidade do leite. Pode-se observar que que o $r=-0,235(p=0,011)$ mostrou que à medida que a pontualidade das empresas compradoras aumenta, menores são as remunerações realizadas por elas sobre as condições de qualidade do leite.

Sobre o tipo de registro, apenas duas condições investigadas na pesquisa apresentaram correlação significativa com a pontualidade da empresa compradora de leite: os produtores que fazem o registro manual das informações geradas nas propriedades e os produtores que não fazem nenhum tipo de anotação. A correlação da pontualidade com os produtores que registram as informações no papel foi de $r=-0,333$ ( $p=0,0003$ ), o que representa que, quanto mais pontual as empresas que compram o leite produzido pelos participantes da pesquisa, menos anotações eles fazem. Da mesma forma, a correlação existente entre a pontualidade e os produtores que não realizam nenhum tipo de anotação foi de $r=0,360(p<0,0001)$ vindo a confirmar a correlação existente na avaliação anterior e implica dizer que, quanto mais pontual as empresas são, menos anotações são realizadas nas propriedades, permitindo o entendimento de que a confiança influencia na realização de anotações nas propriedades.

Sobre os tipos de anotações realizadas nas propriedades e a correlação existente com a pontualidade das empresas que compram leite dos produtores rurais, tem-se que as seguintes anotações apresentaram resultados inversamente proporcionais: despesas e receitas, cios e coberturas, parição e secagem, pesagem da recria, controle leiteiro, temperatura e chuva (clima) e controle de sêmen foram inversamente proporcionais. Na pesquisa realizada, essas anotações são menos realizadas quando a pontualidade das empresas é maior. Apenas as anotações realizadas nas propriedades referentes à vacinação dos animais obtiveram uma correlação diretamente proporcional, ou seja, quanto mais pontuais as empresas compradoras são, mais os produtores 
realizam as anotações das informações a respeito da vacinação dos animais. A Tabela 1 apresenta os coeficientes de correlação das variáveis em questão.

Tabela 1- Coeficientes de Correlação entre a pontualidade das empresas compradoras de leite e as anotações realizadas nas propriedades leiteiras. Alfenas, MG, 2017

\begin{tabular}{cc}
\hline Variáveis & Pontualidade \\
\hline Despesas e Receitas & $r=-0,313(p<0,001)$ \\
Cios e coberturas & $r=-0,268(p=0,004)$ \\
Parição e Secagem & $r=-0,240(p=0,010)$ \\
Pesagem da recria & $r=-0,193(p=0,039)$ \\
Controle leiteiro & $r=-0,239(p=0,010)$ \\
Vacinação & $r=0,351(p<0,0001)$ \\
Clima & $r=-0,212(p=0,023)$ \\
Controle de Sêmen & $r=-0,212(p=0,023)$ \\
\hline
\end{tabular}

Fonte: Dados da pesquisa.

A Correlação inversa também pôde ser identificada quando se considerou a pontualidade das empresas compradoras de leite com os produtores que possuem outra fonte de renda externa ao meio rural. O coeficiente de correlação entre essas variáveis foi $r=-0,226(p=0,015) 0$ que permitiu perceber que, quando a pontualidade das referidas empresas sobre o pagamento do leite aumenta, menores são as fontes de renda provenientes de outras atividades externas à pecuária leiteira e ao meio rural.

No que diz respeito à correlação da pontualidade ao fornecimento de ração concentrada para vacas ordenhadas ( $r=-0,303$ com $p<0,001)$, vacas secas $(r=-0,278$ com $p=0,003)$ e animais em crescimento ( $r=-0,213 \mathrm{com} p=0,022)$, tem-se que, quanto maior a influência da pontualidade dos compradores de leite dos produtores envolvidos na pesquisa, menor é o fornecimento de ração para os rebanhos. O fornecimento de mineral para ao rebanho também obedeceu ao mesmo comportamento das variáveis acima citadas com coeficiente de correlação de $r=-0,332$ ( $p=0,0003$ ).

Ao considerar os resultados correlacionados sobre o conceito apresentado pelos produtores a respeito das empresas que possuem melhor preço e as opções relacionadas à falta de opção na escolha de compradores de leite, obteve-se o $r=-0,256(p=0,006)$. O coeficiente indicou que, quanto melhores são os preços pagos pelo litro de leite oferecidos pelas empresas compradoras, maiores são as opções de escolha para os produtores sobre qual empresa é a mais interessante para realizar uma negociação. Em outras palavras, o aumento significativo dos valores pagos pela produção de leite influenciou no aumento da competitividade entre empresas concorrentes que desejam comprar leite das regiões consideradas na pesquisa.

Já a variável investimento em qualidade do leite apresenta a correlação com a melhor precificação do produto com $r=0,250$ ( $p=0,007)$, fato esse que tornou evidente que os melhores preços pagos pelo litro de leite estão atrelados à qualidade empregada pelos produtores durante o processo produtivo.

A adubação também apresentou influência direta na correlação entre a precificação do produto e a utilização de práticas de produção vegetal de pasto por via de adubação intensiva a qual o coeficiente de correlação situou-se em $r=0,289(p=0,002)$ indicando que utilização da adubação de pastagens influencia no preço do litro de leite pago. 
Ao se considerar o registro das anotações no papel e por um técnico de extensão rural, chegou-se aos valores do coeficiente de correlação de $r=0,298(p<0,001)$ para o primeiro e $r=$ $0,288(p=0,002)$ para o segundo, sugerindo que os altos índices de precificação apresentaram maior preocupação dos produtores com o registro das informações geradas no cotidiano das propriedades leiteiras. Do mesmo modo, a precificação correlacionada com os produtores que não realizam nenhum tipo de registro das informações, percebe-se que os resultados foram de $r=-0,302(p<0,001)$ confirmando o resultado obtido das demais variáveis; assim quanto maior foi a percepção dos produtores sobre os melhores preços praticados no mercado para a comercialização do leite, menos registros das informações presentes nas propriedades foram realizadas.

O coeficiente de correlação dessas variáveis, todas relacionadas com a precificação, encontram-se na Tabela 2, na qual se pode constatar a relação diretamente proporcional das correlações.

Conforme os resultados do estudo, o conhecimento do produtor sobre os custos de produção unitário do leite e os custos totais de produção do leite também obtiveram correlação com a precificação do produto, na qual os valores de $r=0,299(p<0,001)$ para o primeiro e $r$ $=0,255(p=0,006)$ para o segundo indicaram que o nível de conhecimento sobre indicadores econômicos da atividade leiteira dos produtores aumentou à medida que os preços do leite vendidos melhoram.

Tabela 2- Coeficientes de correlação entre preços unitários de venda do leite e as anotações realizadas nas propriedades. Alfenas, MG, 2017

\begin{tabular}{cc}
\hline Variáveis & Melhor Preço \\
\hline Leite vendido e consumido & $r=0,190(p=0,042)$ \\
Despesas e Receitas & $r=0,311(p<0,001)$ \\
Pesagem da recria & $r=0,345(p=0,0002)$ \\
Controle leiteiro & $r=0,265(p=0,004)$ \\
Clima & $r=0,351(p<0,0001)$ \\
Controle de sêmen & $r=0,226(p=0,015)$ \\
Histórico individual dos animais & $r=0,288(p=0,002)$ \\
\hline
\end{tabular}

Fonte: Dados da pesquisa.

A busca de informações sobre a atividade leiteira também apresentou correlação direta com os melhores preços pagos pelas empresas compradoras de leite. O coeficiente de correlação dos recursos televisivos foi de $r=0,261(p=0,005)$, de acesso à internet foi de $r=0,216(p=0,021)$ e aos jornais e revistas de $r=0,289(p=0,002)$. Esses fatores levam a compreender que, quando mais bem remunerados, os produtores se preocupam mais com o acesso à informação e ao conhecimento em relação a situações em que a precificação paga pelo produto vendido foi inferior.

Considerando as práticas nutricionais do rebanho, a utilização de concentrado (ração) para as vacas ordenhadas, quando correlacionada com a melhor precificação pelo leite pago aos produtores, foi de $r=0,311$ ( $p<0,001$ ), seguida da correlação existente entre este e a utilização de farelo de milho ( $r=0,241$ com $p=0,009)$, mineral $(r=0,301$ com $p<0,001)$, substitutos do farelo de milho ( $r=0,219$ com $p=0,019)$ e ureia para a alimentação animal $(r=0,269$ com $p=0,004)$. 
As variáveis que medem a utilização de ordenhadeiras mecânicas do tipo "balde ao pé" ou também conhecidas como "de latão" e as ordenhadeiras do tipo canalizadas, foram antagônicas mostrando que, à medida que melhora a precificação do leite produzido e comercializado, aumenta a quantidade de ordenhadeiras mecânicas canalizadas $(r=0,366, p<0,0001)$ e diminui a utilização de ordenhadeiras mecânicas do tipo "balde ao pé" $(r=-0,314, p<0,001)$.

Outros recursos tecnológicos apresentaram correlação direta com a melhora dos preços de venda do leite indicando que, nas propriedades em estudo, maiores investimentos em máquinas, equipamentos e outras estratégias de manejo que propiciam a evolução do processo produtivo e níveis de tecnificação mais elevados. São eles: utilização de tanques de expansão com $r=$ $0,271$ ( $p=0,003)$; utilização de adubação em pastagens com $r=0,278$ ( $p=0,003)$; utilização de inseminação artificial e controle de acasalamento do rebanho com Coeficientes de correlação de $r=0,198(p=0,034)$ e $r=0,217(p=0,020)$, respectivamente; e aquisição de geradores de energia elétrica com valor de $r=0,276(p=0,003)$.

Sobre o investimento em qualidade do leite, é possível identificar algumas correlações com diversos elementos, em que se destaca a correlação inversamente proporcional da utilização de pastagens extensivas e sem o uso de adubação, sendo o valor de $r=-0,249$ ( $p=0,007$ ), o qual indicou que, quanto maiores são os investimentos em qualidade do leite, menores são as áreas em utilização extrativista das propriedades leiteiras participantes da pesquisa.

A correlação entre investimentos em qualidade do leite e uso do papel para registrar as informações oriundas da pecuária leiteira obteve $r=0,331(p=0,0003)$. Essa correlação indicou aumento significativo do uso de registro das informações na proporção em que os produtores passam a investir mais em qualidade do leite, condição comprovada pelas propriedades em que nenhuma anotação das informações geradas nas propriedades é realizada, cujo $r=-0,332$ $(p=0,0003)$.

Quanto às formas de busca de informações por parte dos produtores, teve-se a correlação entre os investimentos em qualidade do leite e o acesso à internet $(r=0,274, p=0,003)$ e a jornais e revistas $(r=0,271, p=0,003)$ como indicativos de que, quanto mais os produtores buscam informações sobre a pecuária leiteira, mais eles investem em qualidade do leite.

Sobre a condição nutricional do rebanho, os resultados encontrados indicam a correlação direta entre o fornecimento de concentrado (ração) paras as vacas ordenhadas e para os animais em crescimento com correlação também sobre a utilização de mineral, substituto do farelo de milho e ureia, cujos respectivos coeficientes (Tabela 3 ) indicaram que todas essas variáveis sofrem alterações positivas sempre que os investimentos em qualidade do leite aumentam também.

Tabela 3 - Coeficientes de Correlação entre investimentos em qualidade do leite e fornecimento de suplementação para o rebanho. Alfenas, MG, 2017

\begin{tabular}{cc}
\hline Variáveis & Investimento em Qualidade do Leite \\
\hline Ração para vacas ordenhas & $r=0,207(p=0,026)$ \\
Ração para animais em crescimento & $r=0,327(p=0,0004)$ \\
Mineral ao rebanho & $r=0,227(p=0,015)$ \\
Substitutos do farelo de milho & $r=0,276(p=0,003)$ \\
Ureia para suplementação animal & $r=0,252(p=0,007)$ \\
\hline
\end{tabular}

Fonte: Dados da pesquisa. 
Ao observar a utilização tecnológica, constatou-se que os investimentos em qualidade do leite possuem forte correlação com a utilização de ordenhadeiras mecânicas do tipo canalizadas cujo $r=0,481$ ( $p<0,0001)$. Outras variáveis responsáveis pela indicação dos níveis tecnológicos das propriedades foram as seguintes: posse de geradores de energia elétrica $(r=0,285, p=0,002)$, adubação de pastagens em sistemas intensivos de produção $(r=0,351, p<0,0001)$, posse de tratores e implementos agrícolas $(r=0,230, p=0,013)$, utilização de inseminação artificial $(r=0,268$, $p=0,004)$ e acasalamento $(r=0,207, p=0,026)$. Todas essas variáveis apresentaram correlação direta que implica dizer que, nas propriedades investigadas, esses valores aumentam na proporção em que os aspectos relacionados ao aumento dos investimentos em qualidade do leite ocorrem.

\section{DISCUSSÃO}

A busca e o gerenciamento do processo produtivo comprovam a importância desses recursos para o desenvolvimento tecnológico, de gestão e comercialização da produção. A partir dos resultados apresentados, foi possível compreender que as propriedades com os melhores resultados econômicos presentes no estudo ocorreram com produtores que dispõem de várias fontes de informação provenientes de internet de jornais e revistas do setor.

Ao serem consideradas as condições relacionadas à melhoria dos padrões do leite e investimentos na atividade com aspectos relacionados à comercialização, é possível depreender que, quanto mais presentes esses fatores estão no cotidiano das propriedades agropecuárias, melhores são os resultados relacionados à comercialização e ao envolvimento dos produtores com as empresas compradoras de leite.

Esse comportamento foi observado inclusive em algumas situações cujos produtores não vendem o leite para empresa que pagam bonificação por padrões mais elevados de leite. É válido salientar que altos níveis de incremento na qualidade do produto favorecem grandemente as indústrias de beneficiamento do leite, pois, conforme Britt (2017) argumentam, elevados níveis de proteína de alta qualidade presentes no leite são fatores condicionantes da sustentabilidade que regem sobre os laticínios para atender às necessidades alimentares dos seres humanos.

O nível de racionalidade desses produtores que se preocupam com investimentos na melhoria da qualidade do leite permite, inclusive, que práticas sanitárias sejam mais eficientes quando de posse de recursos tecnológicos com essa finalidade. Kashongwe et al. (2017) salientam que as práticas de higienização dos úberes dos animais no momento da ordenha com a utilização de produtos de limpeza, além de melhoria nos padrões do leite, ajudam na erradicação de diversos agentes patogênicos, condição que contribui com níveis superiores de sanidade do rebanho.

A utilização de recursos tecnológicos também pôde ser notada como um diferencial, pois a maior parte dos produtores fazem uso de algum equipamento tecnológico no processo produtivo. Muitos equipamentos puderam ser notados mesmo em propriedades menores, que dispõem de menores escalas de produção e, muitas vezes, não têm condições de possuir equipamentos mais evoluídos, o que permite inferir que mesmo os sistemas de produção mais rústicos necessitam de aparatos tecnológicos um pouco mais evoluídos para a condução de suas atividades dentro das fazendas leiteiras.

É possível identificar que as condições de relação existentes entre compradores e vendedores de leite vêm sofrendo alterações comportamentais de acordo com os níveis de desenvolvimento da atividade, formação e conhecimento dos produtores, evolução tecnológica, entre outros. As práticas de comercialização também se alteram na mesma velocidade em que essas mudanças 
no relacionamento comprador/vendedor ocorrem. Beling e Bender (2010) reforçam essa ideia ao dizerem que há necessidade de modificação dos parâmetros de comercializiação em decorrência da evolução da pecuária leiteira.

\section{CONSIDERAÇÕES FINAIS}

Foi possível constatar que o conhecimento, atrelado à capacidade de inovação tecnológica por parte dos produtores, garantem melhores resultados econômicos para suas atividades leiteiras. Também ocorre o fortalecimento das relações comerciais com as empresas compradoras de leite. Tais condições contribuem o desenvolvimento da cadeia produtiva do leite no Sul de Minas Gerais.

É possível depreender a partir deste estudo que é fundamental que produtores de leite estejam munidos de informações e bom relacionamento com as empresas compradoras de leite para que possam realizar suas atividades com afinco de modo que resultados econômicos e zootécnicos superiores possam ser atingidos.

\section{Agradecimentos}

Agradecemos ao Conselho Nacional de Pesquisa (CNPq), bela concessão da Bolsa de Produtividade (Proc. 303923/2018-0) do último autor.

\section{REFERÊNCIAS}

ARRUDA, M. P.; GIRÃO, L. F. A. P.; LUCENA, W. G. L. Assimetria informacional e o preço das ações: análise da utilização das redes rociais nos mercados de capitais brasileiro e norte-americano. Revista Contabilidade \& Finanças, São Paulo, v. 26, n. 69, p. 317-30, set./dez. 2015.

AZZOPARDI, M.; CORTIS, D. Implementing automotive telematics for insurance covers of fleets. Journal of Technology Management \& Innovation, Santiago, Chile, v. 8, n. 4, p. 59-67, 2013.

BELING, S.; BENDER. M. Estudo da cadeia produtiva do leite no município de Horizontina, com ênfase na análise do segmento de produção primária, 2009. In: ENCONTRO DE ECONOMIA GAÚCHA, 5., Porto Alegre, 2010. Disponível em: https://www.fee.rs.gov.br/eventos/encontro-de-economia-gaucha/5-encontro-deeconomia-gaucha-2010/

BLAND, S. I.; MUMBACH, G. L.; DIEL, M. I.; PORTELA, V. O.; SCHNEIDER, F. J. A.; SILVA, D. R. Dados preliminares sobre características de propriedades de bovinocultura leiteira da região Noroeste do RS. Revista Interdisciplinar de Ensino, Pesquisa e Extensão, Cruz Alta, RS, v. 2, n. 1, s.p., 2015.

BOEHS, C. G. E.; SEGATTO-MENDES, A. P. Identificação de mecanismos de controle em alianças estratégicas para desenvolvimento tecnológico: um estudo múltiplo de casos no setor metal-mecânico ao longo das fases do relacionamento. Revista de Administração Contemporânea, Curitiba, v. 11, n. 3, p. 199-221, jul./set. 2007.

BRITT, J. H. Dairy farming in the midwest and USA in 2067. In: TRI-STATE DAIRY NUTRITION CONFERENCE, 26., 2017, Fort Wayne USA. Anais [...]. Fort Wayne USA: Ohio State University, 2017. p. 11-21.

CÓRDOVA, F.; DURÁN, C.; SEPÚLVEDA, J.: FERNÁNDEZ, A.; ROJAS, M. A proposal of logistic services innovation strategy for a mining company. Journal of Technology Management \& Innovation, Santiago, Chile, v. 7, n. 1, p. 175-85, 2012.

CRUSAFÓN, C. La nueva era mediática: las claves delescenario global. Barcelona: Bosch, 2012. 
DAL MAGRO, C. B.; DI DOMENICO, D.; KLANN, R. C.; ZANIN, A. Contabilidade rural: comparativo na rentabilidade das atividades leiteira e avícola. Revista Online de Custos e Agronegócio, Recife, v. 9, n. 1, p. 2-22, 2013.

DEZIOT, A. E. R. Pequenas empresas de tecnologia da informação e comunicação do estado do Rio de Janeiro à luz do radar da inovação: identificação e análise dos principais obstáculos para os processos de inovação. Revista Eletrônica Sistema \& Gestão, Brasília, v. 9, n. 3, p. 394-405, 2014.

HERMIDA, O. V.; GARCÍA, F. B. Innovaciones comunicativas y cambios de los sistemas socioeconómicos. Interpretaciones de sus efectosenlos textos científicos. Revista de Estudios Sociales, Bogotá, Colômbia, v. 56, n. 2, p. 67-79, abr./jun. 2016.

HUTTER, K.; HAUTZ, J.; DENNHARDT, S.; FÜLLER, J. The impact of user interactions in social media on brand awareness and purchase intention: the case of MINI on Facebook. Journal of Product \& Brand Management, v. 22, n. 5-6, p. 342-51, 2013.

KASHONGWE, O. B.; BEBE, B. O.; MATOFARI, J. W.; HUELSEBUSCH, C. G.. Associations between milking practices, somatic cell counts and milk postharvest losses in smallholder dairy and pastoral camel herds in Kenya. International Journal of Veterinary Science and Medicine, v. 5, n. 1, p. 57-64, 2017.

LEÃO, L. M. S.; MELLO, S. C. B. Institucionalização como mecanismo de controle de marketing. Revista de Administração Contemporânea, Curitiba, v. 14, n. 2, p. 252-67, abr. 2010.

LOPES, V. N.; PACAGNAN, M. N. Marketing verde e práticas socioambientais nas indústrias do Paraná. Revista de Administração de São Paulo, São Paulo, v. 49, n. 1, p. 116-28, jan./mar. 2014.

MACEDO, D. L.; RODRIGUES, L. C.; SILVEIRA, A. Sistema de inteligência acadêmica na gestão de pósgraduação stricto sensu em Administração. Revista de Ciências da Administração, Florianópolis, v. 13, n. 31, p. 136-60, set./dez. 2011.

MACHADO, E. M. Financiamentos de longo prazo para a aquisição de bens e equipamentos com recursos do FAT: um estudo sobre a importância dessa linha de crédito. 2011. Trabalho de Conclusão de Curso (Especialização em Gestão de Negócios Financeiros)- Universidade Federal do Rio Grande do Sul (UFRGS), Porto Alegre, 2011.

MORALES, S. C. V. El análisis y evaluacióndel microambiente empresarial para laestrategia de desarrollo de nuevos mercados geográficos (Examen Complexivo) UTMACH. Machala, Equador: Unidad Académica de Ciencias Empresariales, 2015.

NEVES, M. F. Planejamento e gestão estratégica de marketing. São Paulo: Atlas, 2012.

OLIVEIRA, J. S.; GOMES, A. L.; MEDEIROS, J. G. Análise de eficiência e alocação de recursos na produção leiteira do estado do Rio de Janeiro. In: CONGRESSO DA SOCIEDADE BRASILEIRA DE ECONOMIA, ADMINISTRAÇÃO E SOCIOLOGIA RURAL, 45., 2007, Londrina. Anais [...]. Londrina: IAPAR, 2007.

PINTO, E. C.; GONÇALVES, R. Globalização e poder efetivo: transformações globais sob efeito da ascensão chinesa. Economia e Sociedade, Campinas, SP, v. 24, n. 2, p. 449-79, ago. 2015.

RECUERO, R. Redes sociais na internet. Porto Alegre: Sulina, 2009.

SERRANO, M. M.; HERMIDA, O. V. La mediación comunicativa de las identidades individuales y colectivas. Revista Latina de Comunicación Social, Ilhas Canarias, n. 70, p. 552-565, 2015.

TIDD, J.; BESSANT, J.; PAVITT, K. Gestão da inovação. Porto Alegre, RS: Bookman, 2008. 
ZALUSKI, F. C.; FRAGA, C. R. M.; HEDLUND, P. R.; SANTOS, L. F. I. Análise SWOT no diagnóstico estratégico de uma agroindústria familiar rural. Salão do Conhecimento, ljuí, RS, v. 3, n. 3, s.p., 2017.

\section{Sobre os autores:}

Leandro Carvalho Bassotto: Mestre em Sistemas de Produção na Agropecuária pela Universidade José do Rosário Vellano (UNIFENAS). Especialista em Pecuária Leiteira com Ênfase em Manejo Intensivo de Pastagens pela Universidade Presidente Antônio Carlos (UNIPAC). Graduado em Administração pela Universidade Anhanguera Uniderp. Técnico em Agricultura/Zootecnia pela Escola Agrotécnica Federal de Machado. Coordena o programa Balde Cheio, desenvolvido pela Embrapa Pecuária Sudeste, em parceira com a FAEMG/SENAR, nas cidades de Campestre e Caldas, MG. Tem experiência na área de gestão e extensão rural, desenvolvendo trabalhos de planejamento agropecuário, controles financeiros e análises econômicas para a bovinocultura. Professor do Colégio Comercial Professora Ilma Ambrogi Prado, nas disciplinas de Marketing, Gestão da Qualidade e Teoria Geral da Administração. E-mail: bassootto.Ic@gmail.com

Marina Ariente Angelocci: Doutora em Administração (Marketing) e licenciada em Letras (Português e Inglês) pela Universidade Nove de Julho (UNINOVE). Mestre em Administração com ênfase em Marketing. Graduada em Comunicação Social (Jornalismo) pela Universidade Metodista de Piracicaba (UNIMEP) e em Ciências Contábeis pela Faculdade Anhanguera de Santa Bárbara D'Oeste. Docente nos cursos de graduação da Faculdade Anglo Piracicaba e da Faculdade Anhanguera de Santa Bárbara D’Oeste. Coordenadora do Curso de Comunicação Social- Publicidade e Propaganda- e dos Cursos de Tecnologia em Gestão de Recursos Humanos, Superior de Tecnologia em Logística e Superior de Tecnologia em Marketing da Faculdade Anhanguera de Santa Bárbara D’Oeste. Diretora de marketing da Ok Agência de Notícias. E-mail: msarient@hotmail.com

Luciana de Paula Naves: Pós-Doutora e Doutora em Zootecnia. Mestre em Agroquímica/ Agrobioquímica e Bacharel em Ciências Biológicas pela Universidade Federal de Lavras (UFLA). Atua principalmente nas áreas de: bioquímica animal, metabolismo e nutrição de não ruminantes, avaliação de alimentos e alimentação animal e avicultura. Professora e pesquisadora na Universidade José do Rosário Vellano/Fundação de Ensino e Tecnologia de Alfenas (UNIFENAS/FETA). Participa dos Grupos de Pesquisa certificados pelo CNPq: "Ciência Animal- UNIFENAS", "Metabolismo Animal e Farmacologia Veterinária- UFLA", "Pesquisa na Agropecuária para Agricultura Familiar- UNIFENAS", "Biotecnologia de Microrganismos- UFSJ". E-mail: luciana.naves@unifenas.br

Fernando Ferrari Putti: Doutor e mestre em Agronomia (Irrigação e Drenagem) pela FCA/UNESPBotucatu. Graduado em Administração de Empresas e Agronegócios, pela UNESP-Tupã. Professor Assistente Doutor da Faculdade de Ciências e Engenharia do Campus de Tupã, no Departamento de Engenharia de Biossistemas. Participa dos grupos de Pesquisa do CNPq: Sistemas Fuzzy aplicados nas Ciências Agrárias, BAIA- Instalações, Ambiência e Bem-estar Animal. Docente permanente do Programa de Pós-Graduação (Mestrado) em Sistemas de Produção na Agropecuária e docente permanente do Programa de Pós-Graduação (Doutorado) em Agricultura Sustentável. Professor Visitante do Programa de Pós-Graduação em Horticultura (FCA/UNESP). Atua principalmente nos seguintes temas: manejo de irrigação, água tratada magneticamente, matemática aplicada e computacional, e sistemas fuzzy aplicados às ciências agrárias, estatística e agronegócio. Professor visitante da Universidade José do Rosário Vellano. E-mail: fernando.putti@gmail.com 